\title{
Fé, máscara e vazio em Dostoievski: em torno de O Grande Inquisidor
}

\author{
Katia Marly Leite Mendonça*
}

\section{Resumo}

A obra de Dostoievski se destaca por enfatizar as consequências existenciais e sociais da perda de fé por parte da humanidade. Neste artigo abordaremos alguns temas que giram em torno dessa questão e que são recorrentes no pensamento dostoeivskiano. $\mathrm{O}$ artigo se estrutura em partes onde serão abordados a questão da teopoética de Dostoievski, a dimensão profética da parábola O Grande Inquisidor, o processo de apagamento da face do Cristo, a questão do vazio por trás da hipocrisia, o anticlericalismo dostoievskiano e, por fim, o embate entre os valores da ciência e os da fé presentes em sua obra e refinados em Os Irmãos Karamazov.

Palavras-chave: Dostoievski, teopoética, máscara, fé, vazio.

\section{Faith, mask and emptiness in Dostoyevsky: around The Grand Inquisitor}

\begin{abstract}
Dostoyevsky's work stands out for emphasizing the existential and social consequences of humanity's loss of faith. In this article we will address some themes that revolve around this issue and that are recurrent in the writer's thought. The article is structured in parts where will be addressed Dostoyevsky's theopoetic question, the prophetic dimension of the parable The Grand Inquisitor, the process of erasing the face of Christ, the question of emptiness behind hypocrisy, the Dostoyevsky's anticlericalism, and finally, the clash between the values of science and those of faith present in his work and refined in of The Brothers Karamazov.
\end{abstract}

Keywords: Dostoevsky, theopoetic, mask, faith, emptiness.

* Doutora em Ciência Política pela Universidade de São Paulo, Bolsista de Produtividade do CNPq, Professora Titular dos Programas de Pós-Graduação em Ciências da Religião da UEPA-Universidade do Estado do Pará e em Sociologia e Antropologia da UFPA Universidade Federal do Pará. 


\section{Fe, máscara y vacío en Dostoievski: en torno a El Gran Inquisidor}

\section{Resumen}

La obra literaria de Dostoievski se destaca por enfatizar las consecuencias existenciales y sociales de la pérdida de fe por parte de la humanidad. En este artículo abordaremos algunos temas que giran en torno a esta cuestión y que son recurrentes en el pensamiento dostoeivskiano. El artículo está estructurado en partes donde se abordará la teopoética de Dostoievsky, la dimensión profética de la parábola El Gran Inquisidor, el proceso de borrar el rostro de Cristo, la cuestión del vacío detrás de la hipocresía, el anticlericalismo de Dostoievski y finalmente, el choque entre los valores de la ciencia y los de la fe presentes en su obra y refinados en Los Hermanos Karamazov.

Palabras clave: Dostoievski, teopoética, máscara, fe, vacío.

\section{Teopoética em Dostoievski}

Dostoievski se destaca por enfatizar a ausência de fé do homem e as consequências existenciais e sociais disso. Neste sentido, podemos falar que sua obra é uma teopoética da ausência de Deus na consciência dos homens. A expressão "teopoética da ausência" foi usada por Clooney (2014) para dar conta da poesia de Jorie Graham. Mas, se esta já se encontra mergulhada na condição de atrofia do orgão da fé, Dostoeivski ainda busca, com imensas dúvidas e contradições, crer na existência de Deus. Ao falarmos em atrofia adotamos a expressão de Andrei Tarkovski que se refere a Dostoievski e seus personagens como possuindo uma "consciência atrofiada" "incapaz de crer", que padece de "ausência de espiritualidade" e da "impossibilidade de esperar a graça".

Dostoiévski, por exemplo. Existe uma versão segundo a qual ele é um escritor religioso, ortodoxo, que falou de sua busca e das propriedades de sua fé. Parece-me que não é bem assim. Dostoiévski só conseguiu fazer suas grandes descobertas porque ele foi o primeiro a experimentar e expressar os problemas da ausência de espiritualidade.

Seus heróis sofrem de sua incapacidade de acreditar. Eles querem acreditar, mas perderam o órgão pelo qual se crê. A consciência se atrofiou. E ao longo dos anos, Dostoiévski tornou-se, até certo ponto, cada vez mais compreensível e até mesmo na moda. Isto é precisamente porque esse problema se estende mais e mais. Porque o mais difícil é crer. Porque esperar pela graça é geralmente impossível. Feliz é o homem que conheceu esse estado. Mas poucos podem se gabar. Para se sentir livre e feliz é a intrepidez que importa ${ }^{1}$.

Dostoïevski, par exemple. Il existe une version selon laquelle c'est un écrivain religieux, orthodoxe, qui a parlé de ses recherches et des propriétés de sa f oi. Il me semble que ce n'est pas tout à $f$ ait le cas. Dostoïevski n’a pu f aire ses grandes découvertes que parce 
O próprio Tarkovski, leitor persistente de Dostoievski, recompõe essa ausência de espiritualidade em Stalker, através dos dois personagens, o Cientista e o Escritor, incapazes de crer e de receber a graça divina, livre dádiva de Deus concedida a alguém, independentemente de seu merecimento ${ }^{2}$ - Ora, a literatura dostoievskiana é, com breves exceções, no conjunto, um vasto painel da ausência de fé. Assim é que ao falarmos de Dostoievski, podemos falar de uma literatura teopoética na medida em que ela é a odisséia da busca de Deus não só pelos homens, mas pelo próprio autor, em meio ao pecado, à aridez espiritual e à ausência de graça, enfim uma teopoética da ausência de Deus que é testemunhal e profética, pois dela emerge a percepção de um visionário que assistiu e participou da emergência do processo de secularização e de destruição da fé, detectando o que ocorreria nos séculos vindouros. Ou seja, Dostoeivski esteve aqui e esteve lá. Sua profecia literária quebra a concepção de tempo linear se mostrando atualíssima em pleno século XXI. Com ele podemos falar em teopoética, pois no que tange às artes e literatura, "trata-se não só de um reconhecimento público da força que elas possuem ao lidar com as dimensões, os dilemas e as crises propriamente humanas, mas também de reconhecer seu estatuto de conhecimento sobre tais esferas que nos atingem diretamente" (CONCEIÇÃO, 2010, p.3).

A palavra teopoética teria, segundo Keefe-Perry (2009, p.579), uma dupla dimensão: é ao mesmo tempo adjetivo e substantivo. Ao falarmos de Dostoievski podemos dizer que como adjetivo sua obra é teopoética na medida em que está imbuída de pensamentos e sentimentos religiosos. Como substantivo temos que o escritor faz uma teopoética da ausência de Deus da consciência humana, uma poética do vazio, com brevíssimos momentos reveladores da presença divina como é o caso, por exemplo, da misericórdia expressa por personagens como Marmieladov e Sônia em Crime e Castigo (MENDONÇA, 2018). Em ambas as dimensões temos a expressão literária de uma escritor que busca a fé e que dirá “eu [quero] crer no completo Reino

qu'il était le premier à éprouver et exprimer les problèmes de l'absence de spiritualité. Ses héros souf frent de leur incapacité à croire. Ils veulent croire, mais ils ont perdu cet organe par lequel on croit. La conscience s'est atrophiée. Et avec les années, Dostoïevski est devenu, dans une certaine mesure, de plus en plus compréhensible, et même à la mode. Cela est dû précisément au f ait que ce problème s'étend de plus en plus. Parce que le plus dur est de croire. Parce qu'espérer la grâce est généralement impossible. Bien sûr, heureux est l'homme qui a connu cet état. Mais peu peuvent s'en vanter. Pour se sentir libre et heureux, c'est l'intrépidité qui importe (TARKOVSKI, 1984, tradução nossa).

2 Vide Grace (Theology Of). NEW CATHOLIC ENCYCLOPEDIA, 2003, p. 383 - 401. 
de Cristo" (DOSTOEVSKY, 1975, p. 115) ou, como diria em Os Demônios, através de Chatov:

- Queria saber uma coisa: acredita ou não em Deus? [Stravoguin pergunta a Chatov]

- Creio na Rússia, creio na sua ortodoxia...Creio no corpo de Cristo...Creio que o novo advento será na Rússia...Creio...- balbuciou Chatov, fora de si.

- Mas em Deus? Em Deus?

- Eu...acreditarei em Deus.( DOSTOIEVSKY, 1999, Vol. II, p. 48).

Embora primordialmente sua literatura trate da ausência de Deus, tentar recobrir o percurso teopoético de Dostoievski envolve uma hermenêutica que pode abrir espaço para a crença. Mesmo que o "imediatismo" desta tenha sido perdido, ela pode retornar através de uma interpretação em que podemos receber "o dom do significado [que] é formado pelo símbolo e pela iniciativa inteligível de decifrar". (RICOEUR, 1960, pp. 325-326). Podemos, deste modo, pensar junto com Rubem Alves quando afirma que a teologia é gaiola, que deseja ser ciência e Deus não se deixa apreender em gaiolas. Por seu turno, na teopoética as gaiolas estão vazias, e podemos diante do silêncio "ouvir o canto encantado do pássaro que mora lá" ( ALVES, 1991, 94). Isso é fato em Dostoeivski, mas é fato também que em muitos momentos as idiossincracias religiosas e políticas que adquiriu em seu tempo limitaram o seu pensamento, o encerrando em gaiolas, porém sua obra foi muito maior do que isso. Nós, como leitores, podemos expandir nossas consciências através de uma hermenêutica de sua teopoética.

\section{O Grande Inquisidor: antevisão do mundo contemporâneo.}

Ora, O Grande Inquisidor é um caminho em meio aos subterrâneos da condição humana, este que foi desde sempre o teor da obra dostoievskiana. Esta peça literária vai muito além da crítica à Igreja Católica Romana. Antes, é um quadro sombrio das tensões entre a fé e as instituições, entre a fé e o poder e, neste sentido, entre a fé e a razão calculadora. Embora as críticas de Dostoievski ao catolicismo e ao protestantismo ocidentais sejam marcadas pela sua condição de ortodoxo e de pan-eslavista, sua obra vai para além disso e diz respeito às consequências da ausência de fé na consciência dos homens.

A argumentação de Dostoievski em O Grande Inquisidor é construída sobre as três tentações de Cristo no deserto (Mateus 4, 1-11) e 
corresponderão ao milagre, ao mistério e à autoridade que, respectivamente, serão as pedras de toque deste texto, por si só um clássico e que, embora esteja dentro de Os Irmãos Karamazov, ganhou independência literária.

Com a narrativa de um texto apócrifo que remonta as origens do cristianismo e que foi muito popular no Oriente - A Peregrinação da Mãe de Deus entre os Atormentados - Ivan Karamazov abre a lenda O Grande Inquisidor. Como ressalta Pierre Pascal, os pontos principais indicados no resumo da Peregrinação por Dostoievski revelam a percepção do autor sobre a dimensão espiritual de Maria e conformam o desejo de todos os pecadores, "sem distinção", de serem um dia perdoados ou que ao menos a justiça divina seja suspensa durante a Páscoa assim como "a imensa eficácia da prece em geral e mais ainda da intercessão da Mãe de Deus"3 (PASCAL, 1976, p.58, tradução nossa).

Por exemplo, existe um pequeno poema monástico, sem dúvida traduzido do grego: La Vierge chez les damnés, com quadros duma audácia dantesca. A Virgem visita o inferno, guiada por São Miguel Arcanjo. Vê os condenados e seus tormentos. Entre outras, há uma categoria de pecadores num ago de fogo. Alguns afundam-se no lago e não aparecem mais; são esses "esquecidos pelo próprio Deus”, expressão duma profundeza e duma energia notáveis. A Virgem, banhada em pranto, cai de joelhos diante do trono de Deus e pede perdão para todos os pecadores que viu no inferno, sem distinção.

Seu diálogo com Deus é de um interesse extraordinário. Suplica, insiste e, quando Deus lhe mostra os pés e as mãos de seu filho traspassado pelos cravos e lhe pergunta: "Como poderei eu perdoar a seus carrascos?”, ordena ela a todos os santos, a todos os mártires, a todos os anjos que caiam de joelhos com ela e implorem o perdão para os pecadores, sem distinção. Afinal, obtém a cessação dos tormentos, cada ano, da sexta-feira santa a Pentecostes, e os condenados, do fundo do inferno, agradecem a Deus e exclamam: "Senhor, tua sentença é justa!” (DOSTOIEVSKI, 1971, p. 185).

Os séculos se passaram "e a humanidade o espera com a mesma fé de outrora, uma fé mais ardente ainda, porque quinze séculos se passaram desde que o céu deixou de dar testemunhos ao homem". Durante esse tempo havia, contudo, os sinais do diálogo de Deus com os homens que são os milagres, os santos e as visitas de Nossa Senhora.

\footnotetext{
3 "there is the immense efficaciousness of prayer in general, and more particularly of the intercession of the Mother of God".
} 
Mas o diabo não dorme; a humanidade começou a duvidar da autenticidade daqueles milagres. Naquele momento nascia na Alemanha uma terrível heresia que negava os milagres. "Uma grande estrela, ardente como um facho, caiu sobre as fontes das águas, que se tornaram amarga" (DOSTOIEVSKI, 1971, p.185)

E nasceria o protestantismo que Dostoievski não considerava como uma religião, mas como uma heresia calcada na racionalidade que, como o absinto, contaminaria as águas da fé e prefiguraria a morte do milagre entre os cristãos e, por fim, em toda a sociedade ou, como afirmaria:

Se o catolicismo for destruído, então é claro, o protestantismo será imeditamente destruído também, pois não haveria contra o que protestar. E realmente, o protestantismo, como o vemos, encontra-se nas fronteiras do ateísmo e de bom grado caminha em sua direção, e se ele ainda paira na forma de religião, é somente porque ele se mantem protestando, i.e, brigando e lutando contra o Papa. (DOSTOEVSKY, 1975, p.116, grifos do autor, tradução nossa $)^{5}$.

Max Weber (1987), um ávido leitor de Dostoievski, veria que a secularização não precisaria mais do apêndice religioso para promover o avanço do capitalismo, mas no processo, padres e pastores seriam meros funcionários da "empresa de salvação" que é a igreja, como os tipificará Weber (1982) e terão a marca do selo da razão calculadora que, como percebeu o sociólogo alemão, trará consequências trágicas para a humanidade: desencantamento do mundo e perda do sentido da vida, expressões weberianas para processos que atingirão todas as esferas da vida, não se restringindo ao protestantismo, strictu sensu, mas envolvendo e, segundo Dostoievski, tendo por origem mesma o catolicismo romano. A racionalidade instrumental será para o cristianismo o absinto que conduzirá à perda da fé no mistério. O processo primeiramente atingirá os intelectuais que conduzem e elaboram as reflexões no interior da igreja (padres, pastores e teólogos, etc.) e depois a sociedade.

\footnotetext{
4 "Caiu então do céu uma grande estrela a arder como um facho; caiu sobre a terça parte dos rios e sobre as fontes. O nome da estrela era Absinto. Assim, uma terça parte das águas transformou-se em absinto e muitos homens morreram por ter bebido dessas águas envenenadas" (Apocalipse 8, 10-11).

5 "If Catholicism were destroyed, the of course Protestantism would immediately be destroyed too, for what would it then have to protest against. And really, Protestantism, as we see it, borders on pure atheism and would gladly go over to it immediately, and if it is still hanging on in the form of a religion, it is solely because it is still protesting, i.e., fighting and struggling against the Holy Pope".
} 
Na parábola, movido pela sua Misericórdia, Jesus retorna e o faz durante a Inquisição, em Sevilha. Neste momento Dostoievski o apresenta como a expressão máxima da beleza. "Seu coração está abrasado de amor, seus olhos desprendem a Luz, a Ciência, a Força que irradiam e despertam o amor nos corações. Estende-lhes os braços, abençoa-os, uma virtude salutar emana de seu contato e até mesmo de suas vestes". (DOSTOIEVSKI, 1971, p.186).

Dostoievski, como Tolstoi (2002) em O que é a Arte?, entende o belo como atrelado ao bem. O tema fora elaborado em O Idiota. Em Os Irmãos Karamazov, o Inquisidor não consegue perceber esse mistério. Cego espiritualmente, a única lente que o velho clérigo possui é a do poder:

Mas o Grande Inquisor, o velho homem, o vê e o manda para a prisão, para o escuro calabouço no edifício do Santo Ofício. Mais tarde à noite, vai vê-lo e então "nas trevas, a porta de ferro da masmorra abre-se de repente e o grande inquisidor aparece, com um facho na mão. Está só, a porta torna a fechar-se atrás dele. Pára no limiar e observa longamente a Santa Face. Por que vieste estorvar-nos? (DOSTOIEVSKI, 1971, p. 187, grifos nossos).

Jesus mantém-se calado. Começa então Dostoievski a relatar a grande contradição entre a fé e a razão que se expressa nas organizações religiosas, drama esse que a humanidade haveria de carregar desde sempre, particularmente a partir da modernidade, e que Max Weber (1982) identificou como a transmutação do carisma na racionalidade burocrática, do profeta no funcionário. A palavra estorvo utilizada pelo Inquisidor é impactante e profética já que, hoje mais do que nunca, o Cristo é um estorvo para uma humanidade que é frágil, mas que busca fugir dessa condição através da hybris expressa em um imaginário de autossuficiência assentado no conhecimento racional e em uma felicidade hedonista. O Inquisidor perspicazmente percebe que Jesus torna-se um fardo pesado demais para ser carregado. O Cristo diz "Vinde a mim, vós todos que estais aflitos sob o fardo, e eu vos aliviarei" (Mateus 11, 28), mas, no decorrer da história o processo se inverte e é Ele que se torna um estorvo para a busca de poder e de conhecimento ilimitados pelo homem.

\section{O Apagamento da face de Cristo}

O percurso do pensamento de Dostoievski focaliza os caminhos que adotou o cristinianismo no decorrer dos séculos desfigurando a mensagem do Cristo no grande embate entre as instituições religiosas e a fé. Esse foi um longo processo manifestado em diversas teologias que vão, paulatinamente, 
apagando a face de Cristo e cujos os primeiros produtores e receptáculos são os intelectuais e os clérigos. E, por isso mesmo, pela pouca percepção que se tem do processo e pelas exigências mundiais às quais ele atende, a fase atual, talvez a última, quem sabe, situa-se entre extremos que oscilam entre, por um lado, o velho rosto da intolerância expressa nos fundamentalismos religiosos de diversas ordens e, por outro, o "novo rosto da intolerância", o relativismo (RATZINGER, 2007). Em questão é colocada pelo velho Inquisidor a problemática eterna da liberdade, ou antes, na visão dostoievskiana, da incapacidade humana para a liberdade.

Os deuses desaparecidos serão substituídos pela "deusa ciência" como a nomeou Weber (WEBER, 1982) e isso também foi percebido tanto pela igreja do Oriente quanto do Ocidente. Pavel Florenski (MENDONÇA, 2018; FLORENSKI, 2016) assim como Paulo VI (1964) em Ecclesiam Suam e Karol Wojtyla (2014) orientarão suas críticas para Kant que, como endossou Wojtyla, destruiu a fé ao sustentar que "os fenomena e noumena não dizem nada acerca de Deus" (WOJTYLA, 2014, p. 48). O ateísmo daí decorrente produziria "satélites", que, segundo ele, seriam as diversas formas de idolatria: estatolatria, culto do próprio eu, materialismo, etc. (WOJTYLA, 2014, p. 49 ).

Mas, para Dostoievski, a idolatria será resultante do dilema existente entre a necessidade e a liberdade somado à incapacidade do ser humano em assumir esta última, a qual exige responsabilidade. Ou como diz o Inquisidor: "não há, repito-te, preocupação mais aguda para o homem que encontrar o mais cedo possível um ser a quem delegar esse dom da liberdade que o infeliz traz consigo ao nascer" (DOSTOIEVSKI, 1971, p. 190). Eterno drama da alma humana acerca do qual Tarkovski diria "eu acredito que aqueles que gritam mais fortemente para reclamar liberdade, no fundo, mal a suportam. A liberdade supõe responsabilidade, e é por isso que muitos tem medo dela" (TARKOVSKI, 1993, p. 414, tradução nossa) ${ }^{6}$. Esse dilema, insolúvel, segundo Milosz (1984, p. 55), tem dois extremos: ou a satisfação das necessidades ao custo da liberdade individual, do terror, da mentira e da escravidão como nos regimes totalitários; ou a liberdade ao custo da eliminação do Cristo e, portanto, de um Deus ausente. Dostoievski estava convencido, segundo Milosz que a escolha do Ocidente seria pela crença no homem como redentor e consequentemente pela escravidão.

\footnotetext{
${ }_{6}$ "Je crois que ceux qui crient le plus fort pour réclamer la liberté, au fond, la supportent mal. La liberté suppose la responsabilité, et c'est pourquoi beaucoup en ont peur”.
} 
Em O Grande Inquisidor a fragilidade humana não busca a fé no ato místico da redenção pelo Cristo, fonte de todos os milagres. Antes busca a crença na magia, mais fácil e sem o sacrifício da cruz. Rozanov comentaria “é espantoso que, sem crer no ato místico da redenção (...) o Inquisidor não duvida um instante sequer da tentação, e crê mesmo no valor místico dela, na tentativa de o diabo impedir a vinda do Salvador ao mundo" (ROZANOV, 2004 , p. 223, tradução nossa) ${ }^{7}$. Ora, o Inquisidor ainda tem fé e, embora um impostor, ainda crê no Deus que ele expulsa do mundo... Porém, ele prefigura o dia em que ela desapareceria também entre os Inquisidores. Desapareceria não somente a fé na Ressurreição, mas também na existência do mal, suprimidos em uma sociedade secularizada.

Profecia e literatura se encontram em razão do caráter dialógico, no sentido buberiano, da mentalidade do artista (MENDONÇA, 2017), capaz de entrar em contato com realidades profundas ainda não percebidas pela sociedade de seu tempo. Dostoievski mostra-se um mestre nisso. Escrita tendo como fonte principal o Apocalipse de São João, a profecia contida em $O$ Grande Inquisidor irá se revelar mais evidentemente nos séculos XX e XXI que culminarão não somente no ateísmo, mas na indiferença do homem em relação a Deus. O velho inquisidor, que ainda se mostra portador de algum tipo de fé, será substituído pelo indiferente. O inquisidor ainda se angustia e se revolta em nome do que chama de amor pela humanidade, o indiferente pelo contrário, utilizar-se-á mesmo da religião, e dos ensinamentos antes tidos como sagrados, como fonte de bem-estar, de uma vida voltada para o prazer, algo que caminha junto com o crescimento de teologias da morte de Deus (ALTIZER \& HAMILTON, 1967; MCCULLOUGH \& SCHROEDER, 2004; BERGER, 1980). Não há mais espaço para a revolta e indignação do Velho Inquisidor. Ele também está ultrapassado.

A grande tentação em que se enredou a humanidade se alastra com o Iluminismo e com o avanço da ciência e não haverá lugar para Deus, como identifica a literatura de Dostoievski, para quem não existe uma conciliação entre fé e razão. No embate entre ambas vencerá a última, restando somente os imperativos da frieza e de um cristianismo cuja letra tenta matar o espírito. E este é o cerne de todas as questões dostoievskianas: a perda de fé e a partir disso todas as possibilidades abertas para o mal. As consequências sociais

"Il est étonnat que, sans croire en l'acte mystique de la rédemption (...) l’Inquisiteur ne doute pas un instant de la tentation, et croit même en la valeur mystique de celle-ci, en la tentative du diable d'empêcher la venue du Sauveur dans le monde". 
disso estão diante da humanidade atualmente. De um lado, a eliminação de qualquer solo envolvendo a verdade, mesmo em sua forma mais corriqueira e mundana, como é a verdade factual. Em construção temos um imaginário social da pós-verdade, com a defesa e banalização da mentira travestida em opinião. As consequências sociais disso serão a destruição da esfera pública e o avanço de fundamentalismos políticos e religiosos elaborados ideologicamente em nome de Deus, desde sempre um grande instrumento de poder e de persuasão como revelou o Inquisidor, do qual só restará o simulacro, como profetizado por Ivan Karamazov:

No declínio de seus dias convence-se claramente de que somente os conselhos do grande e terrível espírito poderiam tornar suportável a existência dos revoltados débeis, "desses seres abortados, criados por derrisão". Compreende que é preciso escutar o espírito profundo, esse espírito de morte e de ruína, e, para isto fazer, admitir a mentira e a fraude, conduzir cientemente os homens à morte e à ruína, enganando-os durante o caminho todo, para ocultar-lhes para onde os leva, e para que esses lastimáveis cegos tenham a ilusão da felicidade. Nota isto: a fraude em nome daquele no qual o velho acreditou ardentemente durante toda a sua vida! Não é uma desgraça? (DOSTOIEVSKI, 1971, p. 195, grifos nossos).

A fraude acelera o apagamento da face do Cristo, processo que chega à poesia contemporânea quase que totalmente despido da dúvida existente em Dostoievski, como ocorre com Jorie Graham (RAMKE, 2019), em uma igreja, diante do crucifixo tombado, por ocasião de uma sexta-feira santa: "Desejamos imaginar o apagamento. A terra humana e sua aparência. O humano e seu desaparecimento". (GRAHAM, 2002, p. 94, tradução nossa).

\section{A máscara e o vazio.}

Com o apagamento da face do Cristo, a vida mesma, desaparecida a fé, se transforma também em um estorvo. Dessa percepção de Dostoievski decorre que os temas da morte e do suicídio sejam tão recorrentes em sua obra. Ora, esses são temas que estão presentes também em Swedenborg, que, segundo Czeslaw Milosz, deixa em Dostoievski fortes traços de sua influência, particularmente em Crime e Castigo, escrito à mesma época que Dostoievski adquiriu na Alemanha O Céu e o Inferno de Swedenborg (2002): 
Uma cidade grande fantasmagórica, quer se trate de Paris, literalmente chamada por Baudelaire de 'Cité infernale', ou de São Petersburgo, onde Raskolnikov é atormentado por pesadelos e que parece ser a forma moderna do inferno dantesco; uma descrição disso pode referir-se implicitamente à doutrina das correspondências. Para soar de modo convincente, podemos citar inúmeras passagens de Swedenborg. (...) O que é importante é que o amor de si mesmo, como um tema central, aparece em Crime e Castigo sob duas formas, aquela representada por Raskolnikov, que gradualmente se torna consciente do seu poder, a outra pelo seu duplo, Svidrigailov, que não tem nada a aprender, pois ele conhece a sua natureza maligna e porta um sentimento de condenação eterna. Amor de si mesmo, de acordo com Swedenborg, caracteriza todos os habitantes do reino infernal, que, no entanto, é infinitamente diferenciado. (...) Raskolnikov é um intelectual do século XIX, que rejeitou o céu e o inferno como representado na iconografia cristã e rejeita imortalidade juntamente com eles. A conversa entre ele e Svidrigailov sobre essa questão é uma das mais estranhas na literatura mundial (MILOSZ, 1975, p. 306; 308-309, tradução nossa) ${ }^{8}$.

Cabe aqui retomarmos a passagem referente ao diálogo travado entre Svidrigailov e Raskolnikov acerca da vida após a morte:

- Eu não creio na outra vida - disse Raskólhnikov. Svidrigáilov parecia pensativo.

- E se nela não existissem senão aranhas ou outra coisa do gênero, nada mais? - disse de repente.

“Está doido!”, pensou Raskólhnikov.

- Para mim a eternidade é uma idéia impossível de compreender, algo de enorme, imenso. Mas por que há de ser precisamente enorme? E, de repente, em vez disso, imagine o senhor que existe aí um quarto, no gênero duma sala de banho em pleno campo, negra de fumo e com aranhas por todos os lados,

A big phantasmagoric city, whether it be Paris, literally called by Baudelaire the cité infernale, or St. Petersburg, where Raskolnikov is beset by nightmares, already seems to be the modern form of a Dantesque hell; a description of it may refer implicitly to the doctrine of correspondences. To sound convincing, one ought to quote numerous passages from Swedenborg. (...) What is important is that love of self, as a central theme, appears in Crime and Punishment in two forms, the one represented by Raskolnikov, who gradually becomes aware of its power, the other by his double, Svidrigailov, who has nothing to learn, for he knows his evil nature and has a feeling of eternal damnation. Love of self, according to Swedenborg, characterizes all the inhabitants of the infernal realm, which, however, is infinitely differentiated. (...) Raskolnikov is an intellectual of the nineteenth century who has rejected heaven and hell as depicted in Christian iconography and rejects immortality along with them. The conversation between him and Svidrigailov on that subject is one of the strangest in world literature. 
e que a isso se resumisse a eternidade. Olhe, eu imagino-a muitas vezes assim.

- Mas diga-me, diga-me: não pode imaginar nada de mais consolador e justo?

- exclamou Raskólhnikov com um sentimento doentio.

- Mais justo? Quem sabe, talvez, se não será isto o justo? Olhe, eu tê-lo-ia feito assim, infalivelmente, com toda a intenção - respondeu Svidrigáilov com um vago sorriso.

Um certo frio se apoderou de repente de Raskólhnikov, perante aquela resposta monstruosa. Svidrigáilov ergueu a cabeça, ficou olhando para ele de alto a baixo e, de repente, soltou uma gargalhada (DOSTOIEVSKI, 1994, p. 313).

O nada ou, no máximo, as aranhas, eis o futuro destinado a cada um. Essa é a visão de Dostoievski sobre o homem totalmente separado da relação com Deus. Em O Grande Inquisidor esse simbolismo é atribuído ao "espírito terrível e profundo, o espírito da destruição e do nada" (DOSTOIEVSKI, 1971, p. 188). A simbólica do vazio, do nada, sobressai junto a outro tema recorrente que é o dos espíritos que visitam Svidrigailov e também Ivan Karamazov. A leitura que Milosz faz de Dostoievski o assemelha a Blake, mergulhado no delírio da dúvida e da luta entre a fé no Cristo e, ao mesmo tempo em sua negação (MILOSZ, 1975). O drama de alguém vivendo em pleno processo da divinização do homem e do advento do niilismo europeu com Nietzsche, cuja ideia da morte de Deus precede a de divinização da humanidade.

O vazio revelado no sonho de Svidrigailov possui uma dimensão espiritual que foi retomada posteriormente por Pavel Florenski que, ao meditar sobre a realidade espiritual do ícone, elabora uma tipologia das formas sob as quais a relação com a imagem se apresenta a partir de uma visão que vai para além dos limites do mundo físico:

o rosto, a máscara e o semblante. O rosto (litsó) é o que vemos na realidade terrena, é "quase um sinônimo da palavra fenômeno". É o que se manifesta diante da consciência do homem e diz respeito não só ao rosto humano, mas também a outros seres e realidades como a natureza, por exemplo (o "rosto da natureza"). O semblante (lik) é feito à semelhança de Deus, vem da plenitude divina, tem substância metafísica e vincula-se ao bem. (FLORENSKI, 2016, p.52 apud MENDONÇA, 2018, p.100).

Assim é que encontramos na literatura de Dostoievski o semblante tanto no príncipe Michkin, de O Idiota, como expressão da "beleza que 
salva", vinculada à verdade e ao bem, como em Sonia Semionovna, de Crime e Castigo, transfigurada, como Madalena, pela misericórdia em relação ao próximo (MENDONÇA, 2018, p. 101). A máscara (lichina), contudo, será o extremo oposto do semblante, significando para Florenski “algo que assume um aspecto semelhante a um rosto, parecido com um rosto, que se faz passar por um rosto e por tal é aceito, mas em seu interior está vazio, tanto no sentido da materialidade física quanto no da substancialidade metafísica"( FLORENSKI, 2016, p. 54, tradução nossa). Se o semblante é a expressão fenomênica de uma realidade divina, a máscara é o oposto. Sob ela encontramos apenas o vazio. Mas a característica da máscara é a impostura, o engano, a mentira, algo que para Florenski tem uma dimensão lúgubre na medida em que encobre "algo terrífico", significando larva que na mitologia romana era o mesmo que cadáver astral, "um cliché sem substância deixado pelos mortos, ou seja, uma força escura, impessoal, vampiresca, que busca sangue fresco e um rosto vivo para manter-se, ganhar vida e ao qual esta máscara astral poderia aderir, absorvendo e suplantando esse rosto pelo seu próprio ser". (FLORENSKI, 2016, p.55, grifos do autor, tradução nossa) ${ }^{10}$.

Tanto para Dostoeivski quanto para Florenski, a destruição do homem encontra-se na aliança entre razão calculadora e mal. Stavrogin, de Os Demônios, é o símbolo maior dessa aliança e, junto com O Grande Inquisidor, prefigura o império da máscara (MENDONÇA, 2018, p. 103) que dominaria a consciência humana e as relações sociais modernas, impondo visões do mundo assentadas na mentira e no vazio.

\section{O anticlericalismo dostoievskiano como crítica à máscara}

Instrumentos da razão instrumental, a mentira e a fraude sempre foram temas fortes em Dostoievski. Stavrogin, de Os Demônios, seu mais perverso personagem, é o exemplo profético da assunção delas no mundo. Ora, na abordagem deste tema, quando confrontado com a busca de

\footnotetext{
9 "El sentido originario de esta palabra es el de larva, con lo que se quiere significar algo que toma un aspecto semejante a un rostro, parecido a un rostro, que se hace pasar por rostro y por tal es aceptado, pero que en su interior está vacío, tanto en el sentido de la materialidad fisica como en el de la substancialidad metafisica".

10 "un cliché insustancial dejado por el muerto, es decir, una fuerza oscura, impersonal, vampiresca, que busca sangre fresca y un rostro vivo para mantenerse y cobrar vida, al que esta máscara astral podría adherirse, absorbiéndolo y suplantando ese rostro por su propio ser".
} 
salvação pelo homem e a realidade das instituições que a apresentam, Dostoievski elaborou uma crítica de cunho anticlerical, daí que uma estrutura organizacional como o catolicismo romano provoque sua revolta pois ele tinha claro que a estrutura tende a subverter os ensinamentos do Cristo. Mas aqui cabe mencionar Jacques Madaule quando diz "que estivesse contida na mente de Dostoievski uma crítica ao catolicismo, não é isso o que interessa. Se trata de um juízo sobre o cristinianismo mesmo, sobre sua essência" (MADAULE, 1952, p. 170, tradução nossa). Diríamos mais, a parábola se refere não somente à igreja ou ao cristianismo, mas à humanidade fugitiva de Deus, à eterna apostasia em que o mundo recai constantemente desde a queda de Adão. As chagas e humilhações inflingidas a Cristo estão todas expostas na parábola de Dostoievski e não são chagas apenas da igreja, mas da humanidade. Por isso não se pode ler a parábola unicamente no sentido de uma crítica ao catolicismo romano (ou ao protestantismo em determinadas passagens), embora também o seja.

Enquanto o Padre Zózima é o exemplo maior do religioso cristão para Dostoeivski, Rakitin, o seminarista ambicioso e o Padre Fierapont, o ascético e invejoso monge, revelam as fraquezas humanas presentes por trás dos hábitos religiosos. Tinha Dostoeivski percepção clara do espirito de perversão que ronda o homem, seja fora, seja em meio às instituições, mas encontrando nos papéis destas o ninho adequado para prosperar caindo, ou na ambição e carreirismo como de um Rakitin, ou na hipocrisia ascética de um Fierapont, marcado pelos jejuns, pelo rigor para consigo e, principalmente, pela falta de caridade para com os outros. O papel irá encobrir vícios, manipulações, hipocrisias, taras. Neste sentido, a crítica de Dostoeivski atinge tanto a ortodoxia quanto o catolicismo romano, embora nem todos o leiam dessa maneira, como é o caso de Henry de Lubac que diria: "seus julgamentos sobre a Igreja Católica são, em geral, como se sabe, injustos e difíceis. Eles não fazem nada além de refletir aqueles que usualmente corriam nos meios ortodoxos" (LUBAC, 2012 p. 278) O certo é que, para além disso, Dostoievski, apresenta a tensão entre ciência e filosofia por um lado e religião por outro como, com agudeza, percebeu Milosz (1984, p. 51).

Dostoeivski, era antisecularista, eslavista e ortodoxo. Não poucas vezes se reporta aos jesuítas como sendo antricristãos e conspiradores, em busca do poder e dos bens terrenos. Suas críticas ocorrem em uma época onde esse mito político alcançou seu temps fort. Assim, ele sofreria influência de teólogos 
eslavófilos como Alexei Khomiakov (1900), forte crítico do Ocidente para quem, enquanto a Igreja Católica Romana busca a unidade através da aliança perversa com o poder na terra e o Protestantismo segue o extremo oposto com a ausência de qualquer unidade, a Igreja Ortodoxa buscará a aliança entre o amor e a liberdade (LOSSKY, 1952, p. 38) ou um consenso espiritual antes que uma autoridade exterior (WILLIAMS, 2009). Esse princípio se faz notar claramente nas críticas de Dostoievski ao Ocidente, assim como na visão de seu amigo e contemporâneo Soloviev (2015) acerca do Anticristo.

As críticas de Dostoievski contra o catolicismo romano -- ao qual atribui uma grande responsabilidade no processo de avanço do ateísmoserá encontrada em diversos momentos e direcionada em especial contra os jesuítas. Em O Duplo o tema aparece em Goliadkine: "depois lhe veio à lembrança que os jesuítas até haviam adotado como regra considerar úteis todos os meios, contanto que o objetivo pudesse ser alcançado" (DOSTOIEVSKI, 2013, p. 32). A origem do antijesuitismo de Dostoievski, residiria, segundo Arban (1995, p. 196) na sua juventude quando, ao fazer a revisão de um capítulo para uma enciclopédia, defronta-se com a história de que em 1678 o papa teria condenado uma tese, em vigor na ordem jesuíta, segundo a qual seria permitido desejar a morte do pai, não como pai, mas enquanto possuidor de riquezas.

O mito do jesuíta expressa a profunda decepção e crítica do Oriente em relação à igreja que se afasta do Cristo em busca do poder. Mas o mito é ele também parte do grande drama que emerge com o processo de racionalização e de concomitante secularização da sociedade, com a destruição das tradições e dos laços de fé que poderiam manter unidos os homens a Deus e entre si, processo do qual Dostoievski era um espectador e um profeta e que fazem com que a principal pergunta que subjaz à sua obra seja: como o homem pode manter a fé em meio às instituições? Ou, como a face de Cristo pode se revelar em meio ao cálculo inevitável que carrega consigo o processo de racionalização da vida social?

Em O Idiota, em meio a uma conversa travada em uma reunião de salão, o Príncipe Míchkin ouve contarem que seu benfeitor, Nikolai Pavlíchtchev, a quem ele prezava muito, tinha se convertido ao catolicismo antes de morrer. De início temos o estupor de Míchkin diante da notícia. O velho dignitário que o informa então começa a falar uma série de diatribes contra os jesuítas, após o que Míchkin define o que é cristianismo e porque o catolicismo prega o Anticristo. 
Então, como é que o Catolicismo é uma fé não cristã?_virou-se na cadeira Ivan Pietróvitch.-Então, que fé é?

- Uma fé não cristã, em primeiro lugar!—tornou a falar o príncipe com uma inquietação extraordinária e com uma nitidez fora da medida.-Isso em primeiro lugar; em segundo, o Catolicismo romano é até pior do que o próprio ateísmo, é essa a minha opinião! Sim! É essa a minha opinião! O ateísmo também prega o nada, mas o Catolicismo vai além: prega um Cristo deformado, que ele mesmo denegriu e profanou, um Cristo oposto! Ele prega o anticristo, eu lhe juro, lhe asseguro! Esta é uma convicção minha e antiga, e ela mesma me atormentou... O Catolicismo romano acredita que sem um poder estatal mundial a Igreja não se sustenta na Terra e grita: "Non possumus!’!"11. [...] O ateísmo derivou deles, do próprio Catolicismo romano! Antes de mais nada o ateísmo começou deles mesmo; poderiam eles crer em si mesmos? Ele se fortaleceu a partir da repulsa a eles; ele é produto da mentira e da impotência espiritual! Ateísmo! (DOSTOIEVSKI, 2010, p.607-608).

Para Dostoievski o catolicismo é pior do que o ateísmo não porque nega o Cristo, mas porque o falsifica. Eis a fonte principal do erro que, para ele, teria gerado o inevitável processo de perda de fé e de secularização do Ocidente. A secularização da Igreja já se encontra em sua tentativa de se imiscuir na política mundana, daí a visão de Dostoievski da Igreja Católica como uma continuação do Império Romano Ocidental. E como em tal situação não se gerar o ateísmo, pois na miséria espiritual da organização como poderiam os seus adeptos manter a fé? Implacável, ele percebe a origem do ateísmo nas próprias alianças entre teologia e o poder mundano, que retira a força moral da instituição: "Também isto outra coisa não é senão a união feita com a espada e o sangue. 'Não ouses acreditar em Deus! Não ouses ter propriedade, não ouses ter personalidade, Fratermité ou la mort ${ }^{2}$, dois milhões de cabeças!" (DOSTOIEVSKI, 2010, p. 609). O lema é o carregado pela Revolução Francesa e também pela Revolução Russa que explodirá em 1917. Morto Deus, a função ética da religião será substituída pela do partido, para "extinguir a sede espiritual da humanidade abrasada e então salvá-la a seu modo, não através de Cristo, mas pela violência”. Em suas anotações

11 "Não podemos" é um mote político utilizado pela Igreja desde suas origens contra o poder secular. No tempo de Dostoievski foi usada em particular pelo Papa Pio IX contra incorporação das terras da Igreja à Itália por Napoleão III. Paradoxalmente a ironia de Dostoievski aqui é contra o Papa que, como ele, foi um dos mais ardentes antisecularistas da Igreja e que deixa uma também uma obra de reflexão sobre o tema. Ver o seu Syllabus Errorum (www.vatican.va).

12 Originalmente o mote da Revolução Francesa era "Liberté, Egalité, Fraternité, ou la mort!". 
repetidas vezes ele retoma esse bordão vinculando-o ao catolicismo, vendo neste um terreno para o comunismo e tendo o Papa mesmo "como líder do comunismo" (DOSTOEVSKY, 1975, p. 133 e 134)

Literariamente o anticlericalismo de Dostoievski se orienta por um ideal de homem religioso que sofre a influência de Victor Hugo ${ }^{13}$. Enquanto Os Miseráveis de Hugo é de 1862, o último livro de Dostoievski, Os Irmãos Karamazov é de 1881. Ambas as obras construirão as imagens do religioso perfeito que em muitos pontos se aproximam, pois, também Hugo é anticatólico e anticlerical, encontrando refúgio para sua espiritualidade no espiritismo, ao mesmo tempo em que Dostoievski o encontrava na ortodoxia.

O Bispo Charles-François-Bienvenu Myriel, conhecido como Bispo Myriel ou Monsenhor Bemvindo (Bienvenu), terá na obra de Victor Hugo o papel que terá o staretz Zózima para Dostoievski. Para Victor Hugo, Myriel é o ideal de um verdadeiro cristão, que mesmo ocupando um lugar na hierarquia da Igreja, dentro de limites institucionais elevados, como o são os de um Bispo, fomenta e coloca em prática, verdadeiramente, a caridade sendo o testemunho vivo do Cristo. Algo muito diferente do sórdido arcediago de Notre Dame, Claudio Frollo de O Corcunda de Notre Dame. Ambos, Myriel e Frollo, ocupam posições elevadas na hierarquia, mas enquanto Frollo, como o Grande Inquisidor de Dostoievski, é sórdido e hipócrita, Bienvenu é justo e caridoso, humilde a ponto de renunciar a todas as pompas eclesiásticas, viver pobremente e tudo doar aos pobres, especialmente seu soldo e seu tempo. Hugo dedica um grande e destacado espaço a Myriel, assim como Dostoievski o dedicará a seu antípoda, o Grande Inquisidor. Em ambas as obras as partes, tanto a sobre Myriel como a sobre o Inquisidor, adquirem independência literária em relação às obras maiores na qual se inscrevem. O principal eixo que move as críticas dos dois autores à hierarquia eclesiástica é a questão da hipocrisia que orienta a luta pelo poder. Algo absolutamente em oposição ao Cristo. O Bispo Myriel, de "palavras em harmonia com as ações", como ressalta Hugo, se contrapõe ao mendaz Inquisidor. O primeiro é indiferente ao poder, chega a bispo sem esperar e usa o cargo para ajudar. O segundo primará pela sórdida hipocrisia vestida de salvação para as massas desesperadas (não esqueçamos desse tipo de clérigo povoando o Inferno de Dante em A Divina Comédia). Frollo e o Grande Inquisidor são a expressão da máscara e do vazio que atravessa as instituições. Zózima e Myriel o são da graça e da caridade.

13. Sobre as influências literárias presentes em Os Irmãos Karamazov, ver Victor Terras (1981). 
Subjacente a essas reflexões temos a eterna tensão entre a caridade e a instituição. Paul Ricoeur (1968), que abordou de modo brilhante o tema, percebeu, como Martin Buber também o faria (1982), a possibilidade da presença do amor e da solidariedade em meio aos escaninhos burocráticos e à rotina institucional, algo que Dostoievski encontrou no Padre Zózima e Hugo em Myriel.

\section{À guisa de conclusão}

Para Dostoievski a ciência mataria a fé. Essa certeza subjaz em toda sua obra tendo chegado a sua mais refinada conclusão em O Grande Inquisidor. A questão central é a destruição da relação do homem com o Cristo e a transmutação da fé em Deus na fé na ciência. Anteriormente aos Os Irmãos Karamą̧ov, em suas anotações privadas ele registraria:

"você terá a ciência fora do Cristo e com completa fé. As coisas que devem ser descobertas são as exatas relações cientificas entre as pessoas e uma nova ordem moral - (não há amor, há apenas egoísmo, isto é, luta pela existência) - eles acreditam firmemente na ciência.” [...] A ciência em nosso século refuta tudo o que era anteriormente considerado. Todos os seus pecados são provocados por necessidades insatisfeitas, que são completamente naturais e que, portanto, devem ser satisfeitos. Uma refutação radical do cristianismo e de sua moralidade. Cristo não estava familiarizado com a ciência, eles dizem. (DOSTOEVSKY, 1975, pp. 150- 151, tradução nossa).

Isso será reafirmado, entre outros, por Czeslaw Milosz (1984, p. 52) para quem a verdade científica objetiva envolveria três negações: a do Pecado Original, a da Encarnação e a da escatologia cristã. Estas negações seriam sustentadas pela fé na "vã ciência" como a chamara Dostoievski em Crime e Castigo, cujo resultado para a humanidade seria a construção de uma segunda torre de Babel (MENDONÇA, 2017), tema retomado por ele em $O$ Grande Inquisidor :

A independência, o livre-pensamento, a ciência tê-los-ão desviado num tal labirinto, posto em presença de tais prodígios, de tais enigmas, que uns, rebeldes furiosos, destruir-se-ão a si mesmos, e os outros, rebeldes, porém fracos, multidão covarde e miserável, se arrastarão a nossos pés, gritando: 'Sim, tínheis razão, somente vós possuíeis seu segredo e nós voltamos a vós; salvai-nos de nós mesmos! (DOSTOIEVSKI, 1971, p. 193). 
O caos da existência moderna, traduzido nas violências múltiplas, na era dos extremos e no cenário de pós-verdade, corroboram a imagem da Torre de Babel e destacam a atualidade de Dostoievski, o qual, como bem o frisou Milosz (1984, p. 55), coloca em cena a luta entre dois conjuntos de valores que remetem à questão acerca de quem está com a razão em $O$ Grande Inquisidor: a verdade "objetiva" ao lado do mal ou a verdade metafísica ao lado do Cristo? O resultado do embate entre esses valores, cremos, conduzirá ou à sobrevivência ou à extinção da humanidade.

O certo é que para Dostoievski o homem que alcança certo nível de intelectualidade é jogado em uma cornucópia de abstrações que o afastam da relação dialógica com Deus. Para ele "o ateísmo é uma doença aristocrática, uma doença da alta educação e desenvolvimento e, por isso, deve ser repugnante para o povo comum" (DOSTOEVSKY, 1975, p. 9, tradução nossa $)^{14}$. O conhecimento estimulará a hybris. É exatamente essa a tentação que Satanás apresenta a Jesus em O Grande Inquisidor.

A atrofia da fé em Dostoievski, a sua incapacidade de receber a graça, é também a prefiguração do vazio existencial que a partir de então se construiria nas sociedades dos séculos XX e XXI. Literariamente é o que se encontra no Meursault de Camus (CAMUS, 2017), filho do espírito de indiferença já prefigurado em vários personagens dostoievskianos como Stavrogin de Os Demônios. O Estrangeiro é uma parábola sobre o estorvo que o outro inflige sobre uma vida que perdeu o sentido, sentido que Camus ainda busca na imagem do homem revoltado, mas que para seu adversário e contemporâneo Sartre não existe mais. Antoine Roquentin o personagem de A Náusea (SARTRE, 2006) é a expressão do demoníaco vazio que espreitaria as consciências a partir do século XX (incluindo a do próprio Sartre). Mais do que expressão, será, porém, Roquentin, uma peça importante no grande, vasto, aparentemente portentoso, mas, desencantado e vazio imaginário intelectual contemporâneo. E diga-se que Roquentin terá uma influência considerável, em razão do peso e da centralidade de sua posição europeia, sobre o mundo e sobre as teias de poder acadêmico e intelectual. Um grande tijolo, como o foram também Heidegger e outros, na construção do muro, para usar o termo do próprio Sartre (1961), erguido pelo vazio iniciado com os chamados mestres da suspeita que irão ler Dostoeivski de um modo reducionista. Freud (1990) dele fará uma leitura circunscrevendo-o

14 "Atheism is an aristocratic disease, a disease of higher education and development, and therefore, it must be repugnant to the commonfolk". 
às questões da libido e do parricídio. Nietzsche (STELINO, 2008; SENA, 2010; MURPHY, 2001) inicialmente se entusiasmará por ele ao ponto de considerá-lo como "o único que me ensinou algo de psicologia". Talvez tenha Nietzsche encontrado inspiração para o seu Cristo de $O$ Anticristo em Michkin, assim como na discussão entre Shatov e Stavrogin em Os Demônios. Cedo, porém, se desencantará tomando-o como "um escritor competamente cristão de sentimentos, preso pela moral dos escravos" (LUBAC, 2012, p.256) e por encontrar no pensamento de Dostoievski o cristianismo que rejeita e despreza, afinal O Grande Inquisidor é um elogio a Jesus, como diz Ivan Karamazov a Aliocha.

A destruição da fé no Cristo e sua substituição por um Cristo humano e histórico (como o de Ernst Renan) teria como resultado para Dostoievski a destruição dos laços sociais (que posteriormente seria denominado de anomia por Durkheim). Assim ele dirá em um artigo intitulado Uma das Falsidades Atuais, publicado em O Diário do Escritor:

Lembrem-se, senhores, que todos esses exaltados professores europeus nossos - nossa luz e nossa esperança - todos esses Mills, Darwins e Strausses às vezes têm uma visão muito estranha das obrigações morais de uma pessoa de hoje. [...] As pessoas vão me dizer, talvez, que esses pensadores certamente não estão propagando noções más; que, por exemplo, mesmo que Strauss [David Friedrich Strauss (1808-74)] odeie a Cristo e estabeleça como objetivo da vida de zombar e desprezar o cristianismo, ele adora a humanidade como um todo e seu ensino é tão elevado e nobre como pode ser. É muito possível que tudo isso seja verdade e que os objetivos de todos os líderes atuais do pensamento europeu progressista são filantrópicos e magníficos. Mas o que acredito estar certo é isto: se você desse a todos esses grandes professores contemporâneos instrumentos para destruir a antiga sociedade e construí-la novamente, o resultado seria tão obscuro, tão caótico, algo tão bruto, cego e desumano que toda a estrutura entraria em colapso ao som das maldições da humanidade antes que ela pudesse ser concluída. Depois de ter rejeitado a Cristo, a mente humana pode chegar a distâncias inacreditáveis. Isso é um axioma. (DOSTOEVSKY, 1993, p. 288, tradução e grifos nossos) $)^{15}$.

15 "Keep in mind, gentlemen, that all these exalted European teachers of ours-our light and our hope-all these Mills and Darwins and Strausses sometimes have a very strange view of the moral obligations of a person of today.[...] People will tell me, perhaps, that these thinkers are certainly not propagating evil notions; that, for example, even if Strauss does hate Christ and has set himself the life's goal of mocking and despising Christianity, he nevertheless worships humanity as a whole and his teaching is as elevated and noble as can be. It's very possible that all this is true and that the goals of all today's leaders of 
Este axioma, leitmotiv de toda a obra dostoievskiana, subjaz à frase de Ivan Karamazov, " Se não há imortalidade da alma, então não há virtude, o que quer dizer que tudo é permitido" (DOSTOIÉVSKI, 1971, p. 67, grifos nossos). Aqui a união entre profecia e literatura se dá na gratuidade da obra de arte. Dostoievski, mesmo com as suas inevitáveis idiossincrasias, testemunha isso para nosso século; "a sua profecia, como diz Tarkovski (1993, p. 414) se faz mais atual do que em seu tempo".

\section{Referências}

ALTIZER, Thomas J.J. \& HAMILTON, William. Teologia Radical y La Muerte de Dios. Barcelona: Ediciones Grijalbo, 1967.

ALVES, Rubem A. O Poeta, o Guerreiro, o Profeta. Petrópolis, RJ: Editora Vozes, 1991.

ARBAN, Dominique. Dostoievski. Paris: Seuil,1995.

BERGER, Peter. El dosel sagrado. Elementos para una sociología de la religión. Buenos Aires: Amorrortu editores.1980.

BUBER, Martin. Eu-Tu. Tradução Newton Aquiles Von Zuben. São Paulo: Centauro, 2001. Do diálogo e do dialógico. São Paulo: Perspectiva, 1982.

CAMUS, Albert. O estrangeiro. Trad. Valerie Rumjanek. Rio de Janeiro: Record, 2017.

CLOONEY, Francis X. His Hiding Place Is Darkness: A Hindu-Catholic Theopoetics of Divine Absence. Stanford, CA: Stanford University Press, 2014.

CONCEIÇÃO, Douglas Rodrigues da. "Literatura e religião em discussão: revisitando interpretações, métodos e teorias”. Cadernos da FaEL, v. 3, p. 1-23, 2010.

DOSTOIÉVSKI, Fiódor M. Os Irmãos Karamazóvi. Tradução de Natália Nunes e Oscar Mendes. São Paulo: Abril Cultural, 1971.

O duplo. Tradução de Paulo Bezerra. São Paulo : Editora 34, 2013.

DOSTOIEVSKI, Fiódor. Crime e Castigo. Trad. Natália Nunes. São Paulo: Círculo do Livro, 1994.

DOSTOEVSKY, Fyodor; Proffer, Carl R. (editor). The Unpublished Dostoevsky; Diaries and Notebooks (1860-81), Volume II. Translator Arline Boyer and Carl Proffer. Ann Arbor, MI: Ardis Publishers, 1975.

progressive European thought are philanthropic and magnificent. But what I believe to be certain is this: if you were to give all these grand, contemporary teachers full scope to destroy the old society and build it anew, the result would be such obscurity, such chaos, something so crude, blind, and inhuman that the whole structure would collapse to the sound of humanity's curses before it could ever be completed. Once having rejected Christ, the human mind can go to amazing lengths. That's an axiom". 
. “One of Today's Falsehoods". In: A Writer's Diary, Volume One I 873- I 876. Tradução de Kenneth Lantz. Evanston, Illinois: Northwestern Universitv Press, 1993.

DOSTOIEVSKY, Fiódor. Os Possessos. 3 volumes. Lisboa: Editora Europa América, 1999. FLORENSKI, Pável. E1 Iconostasio, Una Teoría de la Estética. Salamanca: Ediciones Sígueme, 2016.

FLORENSKIJ, Pavel. Le porte Regali; saggio sull'icona. Milano: Adelphi Edizioni, 1977.

FREUD, S. "Dostoievski e o Parricídio". In: Obras Completas ESB. Rio de Janeiro: Imago, 1990. v. XXI

GRAHAM, Jorie. Never: poems. New York: Parker Hill, 2002.

HUGO, Victor. Os Miseráveis: 2 Volumes. São Paulo: Cosac Naify, 2012.

KEEFE-PERRY, L. B. C. "Theopoetics: Process and Perspective". In: Christianity and Literature, vol. 58, n. 4 (Summer 2009), p. 579-601.

KHOMIAKOV, A. S. On the Western Confessions of Faith [publicado originalmente em 1900] Disponível em: http://archangelsbooks.com/articles/east_west/WesternConfessions_ Khomiakov.asp. Acesso em: 20.03.2019.

LOSSKY, N.O. History of Russian Philosophy. London: George Allen and Unwin Ltd, 1952.

LUBAC, Henri de. El drama del Humanismo Ateo. Madrid: Ediciones Encuentro, 2012.

MADAULE, Jacques. El Cristianismo de Dostoievsky. Trad. Juan Paredes. Buenos Aires: Editorial Lousada.1952.

MCCUlLOUGH, Lissa \& SCHROEDER, Brian. Thinking Through the Death of God: A Critical Companion to Thomas J. J.Altizer. New York: State University of New York, 2004.

MENDONÇA, Katia. "Arte e ética no pensamento de Tarkovski”. In. Avanca Cinema 2014. Portugal, Avanca: Editora Cine Clube de Avanca, 2014, pp. 83-91.

. A imagem; uma janela para o invisível. Belém-Pará: Marques Editora, 2018.

" "Duas luzes em meio à escuridão: Etty Hillesum e Sônia Siemiônovna". In John David Barrientos Rodríguez, Diego I. Rosales Meana y Ángel Viñas Vera (eds.). La filosofía y el Bien, Agradecimientos a Miguel García-Baró. Madrid: Ápeiron Ediciones, 2018.

. "Crime and Punishment: Prophecy and Mercy in Dostoyevsky". In: Mundo Eslavo, 16 (2017), 163-171. Disponível em : http://mundoeslavo.com/index.php/meslav/article/ view/244 Acesso em: 20.12.2018.

MILOSZ, Czeslaw. The Land of Ulro. Translated by Louis Iribarne. New York: Farrar, Straus and Giroux, 1984.

. "Dostoevsky and Swedenborg”. Slavic Review, Vol. 34, No. 2 (Jun, 1975), p. 302-318. Disponível em: http://www.swedenborgstudy.com/articles/history-of-art/cm75.htm. Acesso em 23.04.2019.

MURPHY, Tim. Nietzsche, metaphor, religion. New York: State University of New York Press, 2001.

NEW CATHOLIC ENCYCLOPEDIA. New York: Thonsom, Gale in association with the Catholic University of America, 2003. 
PASCAL, Pierre. The Religion of the Russian People. Crestwood, New York : St. Vladimir's Seminary Press, 1976.

PAULUS PP. VI. Carta Encíclica Ecclesiam Suam. Vaticano: Libreria Editrice Vaticana, 1964.

RAMKE, Bin. "Celebrating a World in Danger". In: Boston Review. October 1, 2002. Disponível em: http://bostonreview.net/poetry/bin-ramke-celebrating-world-danger. Acesso em 28.08.2019.

RATZINGER, Joseph. "El relativismo, nuevo rostro de la intolerancia", Zenit, 1.XII.02. Disponível em: http://www.interrogantes.net/Joseph-Ratzinger-El-relativismo-nuevo-rostrode-la-intolerancia-Zenit-10XII002/menu-id-29.html. Acesso em: 23.04.2019.

RICOEUR, Paul. La Symbolique du Mal. Paris: Aubier, 1960.

História e Verdade. Rio de Janeiro: Forense, 1968.

ROZANOV, Vassili. "A propos de 'La Légende du Grand Inquisiteur". In. LEONTIEV, Konstantin et alii. La Légende du Grand Inquisiteur de Dostoïevski. Lausanne, Suisse: Editions L'Age d'Homme, 2004.

SARTRE, Jean-Paul. A náusea. Rio de Janeiro: Nova Fronteira, 2006.

O Muro. São Paulo: Civilização Brasileira, 1961.

SOLOVIEV, Vladimir. Los tres diálogos y el relato del Anticristo. Barcelona: Editorial Scire/Balmes, 2015.

SENA, Allan Davy Santos. "O Jesus de Nietzsche e o príncipe Míchkin de Dostoiévski". Revista Trágica: estudos sobre Nietzsche $-1^{\circ}$ semestre 2010 - Vol.3 - nº - p. 21-40.

STELINO, Paolo. "El descubrimiento de Dostoievski por parte de Nietzsche". Contrastes Revista Internacional de Filosofía, vol. XIII (2008), p. 79-99.

SWEDENBORG, Emanuel. Del Cielo y del Infierno. Madrid: Ediciones Siruela, 2002.

TARKOVSKI, Andreï. Discours sur l'Apocalypse, 1984. Disponível em: http:// newsoftomorrow.org/arts/cinema/andrei-tarkovski-discours-sur-lapocalypse]. Acesso em: 10.09.2019.

Journal (1970-1986). Paris: Cahiers du Cinéma, 1993.

TERRAS, Victor. A Karamazov Companion: Commentary on the Genesis, Language, and Style of Dostoevsky's Novel. Wisconsin: The University of Wisconsin Press, 1981.

TOLSTOI, Leon. O que é a arte? São Paulo: Ediouro, 2002.

WEBER, Max. A Ética Protestante e o Espírito do Capitalismo. São Paulo: Pioneira, 1987.

Economia y Sociedad. México: Fondo de Cultura Económica, 1982.

WILLIAMS, Rowan. Dostoevsky: Language, Faith and Fiction. London: Baylor University Press, 2009.

Submetido em 15-11-2019

Aceito em: 14-5-2020 